\title{
Academic Dishonesty: A Preliminary Researchers View
}

\author{
Shawren Singh ${ }^{1}$ and John Mendy ${ }^{2}$ \\ ${ }^{1}$ University of South Africa, Florida, South Africa \\ ${ }^{2}$ University of Lincoln, UK \\ singhs@unisa.ac.za \\ jmendy@lincoln.ac.uk \\ DOI: 10.34190/RM.19.031
}

\begin{abstract}
Increasingly academe is facing the challenge of dealing with allegations of plagiarism and academic dishonesty. Academic dishonesty plagues both the degree acquisition process as well and the publishing process. Academic dishonesty within the university space has been clouded in mystery, as many universities are not willing to break the code of silence. However, within the academic publishing space, several respectable journals had to withdraw published papers citing academic dishonesty as a concern. At the core of academic dishonesty is the researcher and their perceptions of issues affecting academic dishonesty. The purpose of this research is to develop a better understanding of researchers' attitudes to issues of academic dishonesty. This study is quantitative in nature and primary data in the form of Likert scale questions were collected from developing researchers. The questionnaire data were statistically analysed, and a framework was developed to outline emerging researchers' perceptions of academic dishonesty. Key findings included academic dishonesty is influenced by several issues such as academic pressure, electronic deterrents, writing challenges, outsourcing, data challenges, plagiarism, database challenges, and electronic sources. This is important because by better understanding researchers' perceptions to academic dishonesty, (1) appropriate training interventions can be implemented (2) higher quality research will be produced and (3) research funding will not be wasted.
\end{abstract}

Keywords: Perceptions of Plagiarism, cheating, Academic Integrity, Ghost Writing, Academic Ethics, Academic dishonesty

\section{Introduction}

Academic dishonesty in the form of plagiarism, ghost-writing, or data fabrication has an indelible impact on the images of a university. For example, Duke University recently agreed to pay back the US government \$112.5 million to settle claims that the universities researchers used fabricated data to attract several government grants (Casadevall, 2019). It is not uncommon to find sensationalist media coverage of academic dishonesty (see Exhibit A). Merely by being associated with a university that has been involved with academic dishonesty, all the academic staff appears to be guilty by association (Molet et al., 2013). Casadevall (2019) aptly points out "this is a communal punishment for an institution where the overwhelming majority of scientists are honest, hard-working individuals seeking knowledge for the good of humanity." With the increasing acceptance of digital scholarship (Remenyi and Susan, 2016), universities that are involved with or appear to be involved with less than acceptable practice are named and shamed. The internet is unforgiving, as these naming and shaming events stay on the internet for perpetuity leaving a digital scare against the good name of the university.

\section{Background}

Academic research is the process of adding something of value to the existing body of theoretical and practical knowledge in response to a question or series of questions. Academic research follows a formal process which includes the establishment of an auditable research methodology to answer the research questions (Remenyi, 2017). The methodological approach adopted by a researcher is sometimes prone to abuse, some researchers have used flawed research methods (W5, 2011; W4, 2018) or sophisticated data dredging techniques (Head et al., 2015) to make their research appear more relevant. In the pursuit of presenting relevance's, the research has become dishonest.

An important characteristic of academic research is that the research needs to be presented in a matter that demonstrates a respectable level of scholarship on the part of the researcher(s) (Remenyi, 2017). Scholarship is displayed in two forms. These are academic writing and by the appropriate use of research methodology, both of which are not trivial tasks. The scholarship enterprise can fall victim to academic dishonesty. Academic dishonesty can broadly be described as a form of cheating that occurs within the academic space. Academic dishonesty could include (but not limited to): fabrication, deception, sabotage, bribery, collusion, improper use of information, communication and technology and plagiarism (W1, 2019; W2, 2019). As a subset of academic dishonesty, plagiarism refers to the use of other people's ideas and words without giving the original author appropriate acknowledgment (Randall, 2001; Clarke, 2006). If ideas are used in an essay or dissertation that 
have been found in the published work of another author(s), it is academic dishonesty not to specifically acknowledge the original source(s). It is important that the acknowledgment must follow the rules of the referencing system employed in the work (Singh and Remenyi, 2016). Interestingly some point out that there is the issue of unintentional plagiarism when the researcher disregards accepted scholarly procedures (W3, 2019). Although the use of ideas without acknowledging them is an offense, it is even worse if the actual words of other authors are copied without acknowledgment (Singh and Remenyi, 2016). There are several grey areas that constitute academic dishonesty but are not adequately understood.

Academic dishonesty is influenced by several factors, see Figure 1, some of these factors are: academic pressure, electronic deterrents, writing challenges, outsourcing, data challenges, plagiarism, database challenges, and electronic sources. Each of these factors will be briefly discussed.

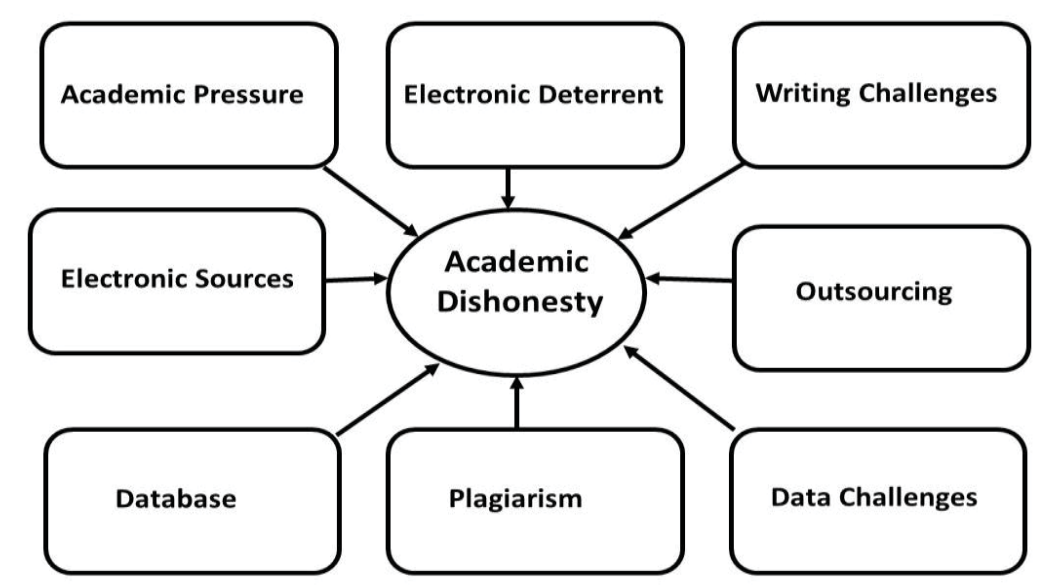

Figure 1: Factors Affecting Academic Dishonesty

There are gaps in the literature about how researchers feel about plagiarism (Lei and Hu, 2014; Mouton, 2017). There is a disproportionate number of pages published about students' perceptions to and involvement with academic dishonesty. It is understandable that universities and academics approach the issue of academic dishonesty within their ranks cautiously.

There is increasing academic pressures on individuals to "publish or perish"(Dinis-Oliveira and Magalhães, 2016; Grimes, Bauch and loannidis, 2018). Academics who are under-resourced find themselves under pressure to effectively manage tuition, research, academic citizenship and community engagement (Cawood et al., 2008; Santoso and Cahaya, 2018). Due to limited funding from governments and abused subsidy models, academics are treated as units of production in order to claim government subsidies (Hedding., 2019). These ongoing sources of pressure have an impact on the quality of research that universities produce. There has been an argument that electronic deterrents can be used as a tool to reduce academic dishonesty.

Publishers (Supak Smolcic and Simundic, 2013; Kalnins, Halm and Castillo, 2015) and academics are using electronic deterrents to curb academic dishonesty. In a recent conversation with a senior professor, the professor erroneously claimed that "...we have solved the plagiarism problems, we use Turn-it-in". Software deterrents to plagiarism are one tool in the academics arsenal, however, it must be noted that tools like Turnit-in and iThenticate "does not detect plagiarism, but it does highlight matches in text between the article that has been uploaded" (Lammey, 2014) to articles within the data repository. Software can be used to reduce gross plagiarism (Santoso and Cahaya, 2018). However, any reasonable attempt to reduce academic dishonesty would require a joint initiative between academic publishers, editors (Jarić, 2016) and researchers.

Researchers who are the custodians of the knowledge-generation process may at times in their research career have challenges when it comes to writing.

It has been said that 'writing is a full body contact sport' and within the research writing space there is inadequate attention paid to formal training for writing (Aitchison, 2015). For example, research writing retreats require a high initial investment and many universities are shackled by limited resources, which results in academics taking longer to develop the required academic writing competence (Kornhaber et al., 2016). A 
further concern is that international journals are predominantly in English, posing a barrier for second language English research writers (Jeyaraj, 2018). In a desperate effort to bridge some of the writing challenges, some researchers have attempted to outsource aspects of their writing.

Some authors have resorted to outsourcing their writing by using ghost-writers to assist with the writing of their research (Singh and Remenyi, 2016; Sarwar and Idris, 2018). Ghost-writing is the practice of hiring a writer (or writers) to produce a piece of work that follows a predefined style, and none of the original writing credit is attributed to the ghost-writer/s. Detecting ghost-writing is difficult because the peer reviewer is not acquainted with the authors writing style (Singh and Remenyi, 2016).

A further challenge for researchers relates to data. There are two issues under data, one is data overload and the other is false information. Data overload comes in the form of scientific and pseudo-scientific academic articles being published, and it is argued by some researchers that only a small fraction of these papers represents a contribution to the scientific body of knowledge. False information is represented by predatory and counterfeit journals (Singh, 2017). Researchers need to navigate the different data repositories to find respectable scientific papers.

Plagiarism and its consequences are becoming increasingly complex (Robinson-Zañartu et al., 2005) and difficult to identify. There are gaps in the literature regarding the factors that force some researchers to commit acts of plagiarism, partly due to the disproportionate level of research focusing on student perceptions of plagiarism (Husain, Al-Shaibani and Mahfoodh, 2017) rather than researcher perceptions. It may be argued that researchers understand the consequences of plagiarism and therefore there is no need for research in this area or a plagiarist has no reason the further expose their universities and/or themselves.

Like any type of technology, academic databases are constantly changing. To adequately search the different databases, researchers are required to understand the interfaces of different academic databases. Understanding the different databases is not an easy task as each database has a distinct vocabulary and interface (Singh, 2017). The complexity of the database interface affects the literature review journey.

Increasingly the extent literature has become electronic. The search for literature takes the researcher through two paths, the traditional academic publishing path and the open access academic publishing path. Within these spaces, it is estimated that there over 50 million published academic articles (Jinha, 2010) and this number is growing. These articles are housed in special databases. UlrichsWeb is a library directory that provides information on active academic journals, and there appear to be 1296 databases and 971 online databases. The Gale Directory of Databases claims to cover more than 20000 databases. This large amount of data poses a challenge to the researchers (Singh, 2017) and emerging researchers who can be easily overwhelmed by the vastness of the literature.

\section{Methodology}

When undertaking any research, it is prudent to have an acceptable research strategy (Myers, 2009; Yin, 2011), Figure 2 outlines the strategy adopted in this research. There are three phases in this research, phase 1 understanding aspects of the literature; exploring researcher perceptions and phase 3 future data collection and analysis. Only phase 1 and phase 2 will be reported upon in this paper. Phase 1 of the research is qualitative in nature. It was important to use a qualitative approach in this phase of the research because the researchers wanted to develop a better quantitative understanding of researchers' perceptions of issues affecting academic dishonesty. Phase 1 constituted a review of the extent literature and a brainstorming session, in order to develop a questionnaire focused on issues that affect academic dishonesty.

In this research, a 5-point Likert scale questionnaire was used for data collection. Using a 5-point Likert scale questionnaire for data collection is an acceptable approach (Sachdev and Verma, 2004; Bouranta, Chitiris and Paravantis, 2009). Likert scales were used because the literature suggests that 5-point scales are less confusing to understand, can increase response rates and is easy to use by respondents (Babakus and Mangold, 1992; Devlin, Dong and Brown, 1993). The 5-point Likert response format ranged from "strongly agree = 5" to "strongly disagree $=1$ ". The questionnaire was piloted and refined accordingly. The final version of the instrument was a one-page questionnaire comprised of 3 sections: a section for demographic data, 26 items on a 5-point Likert scale and a section for comments. 
In phase 2 of this research, the questionnaire was administered, the data was collected and then analysed.

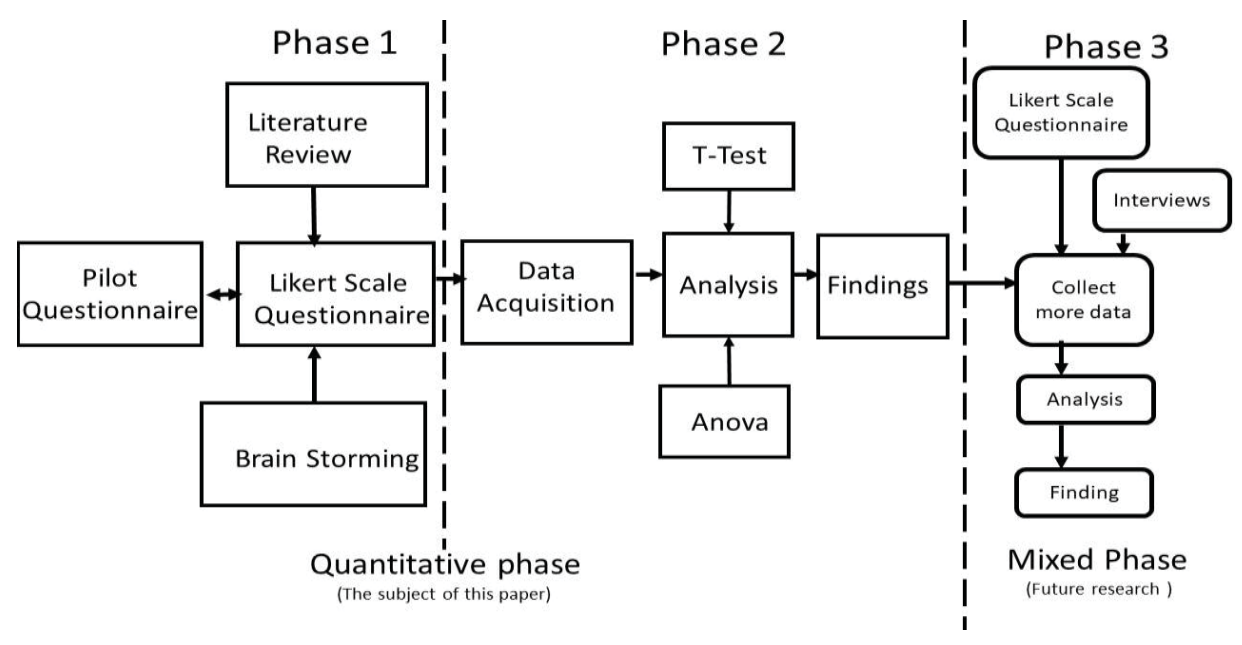

Figure 2: Research Approach

\subsection{The data collection instrument}

The questionnaire comprised 26 items (see Table 1) and the items in the questionnaire were classified as follows: Research Pressures, Electronic Deterrent, Writing Challenges, Outsourcing, Data Challenges, Plagiarism, Database, and Electronic Sources. For each question, respondents had the option of Strongly agree, Agree, Undecided, Disagree and Strongly disagree.

Table 1: Questionnaire Instrument

\begin{tabular}{|c|c|c|}
\hline Question & Categories & Likert Scale Items \\
\hline Question 1. & \multirow{5}{*}{ Pressure } & I feel pressured to publish. \\
\hline Question 2. & & I feel pressured to publish within a shorter time frame. \\
\hline Question 3. & & I feel pressured by my line manager to publish. \\
\hline Question 26. & & $\begin{array}{l}\text { I feel pressured to do other university activities such as administration or } \\
\text { community engagement }\end{array}$ \\
\hline Question 5. & & I do not understand the academic review process. \\
\hline Question 7. & \multirow[t]{2}{*}{ Electronic Deterrent } & Turn-it-in is a useful tool for me to avoid plagiarism. \\
\hline Question 8. & & iThenticate is a useful tool for me to avoid plagiarism. \\
\hline Question 4. & \multirow[t]{2}{*}{ Writing Challenges } & I find academic writing challenging. \\
\hline Question 6. & & I have received insufficient training in academic writing. \\
\hline Question 24. & \multirow{4}{*}{ Outsourcing } & It is ok to hire a third party to collect my data. \\
\hline Question 25. & & It is ok to hire a professional to write aspects of my research. \\
\hline Question 11. & & It is ok to crowdsource aspects of my literature. \\
\hline Question 21. & & It is ok to hire professional academic writing services to assist me write. \\
\hline Question 9. & \multirow{3}{*}{ Data Challenges } & I feel overwhelmed with the amount of data that I must manage. \\
\hline Question 15. & & Librarians are key academic resources. \\
\hline Question 10. & & I find it difficult to identify false information. \\
\hline Question 17. & \multirow{4}{*}{ Plagiarism } & I have received insufficient training in anti-plagiarism. \\
\hline Question 18. & & Copying others' work without citing them constitutes plagiarism. \\
\hline Question 19. & & There are serious consequences if I violate plagiarism policy. \\
\hline Question 20. & & Copying my own submitted work does not constitute plagiarism. \\
\hline Question 12. & \multirow{3}{*}{ Database } & I do not understand how to use academic databases. \\
\hline Question 13. & & The language used to search academic databases is hard to learn. \\
\hline Question 14. & & The academic database interface is complicated. \\
\hline Question 16. & \multirow{3}{*}{ Electronic Sources } & Google Scholar is a legitimate academic resource. \\
\hline Question 22. & & I do not trust open access journals. \\
\hline Question 23 & & $\begin{array}{l}\text { I only trust the established academic publishing companies i.e Elsevier, Springer, } \\
\text { Wiley-Blackwell, Taylor \& Francis and Sage }\end{array}$ \\
\hline
\end{tabular}

The scores for questions 5, 6, 10,12,17,20 and 22 were reversed as they were stated in the negative.

\subsection{The Sample}

The selection of appropriate informants for any academic research is a challenging and time-consuming task for a researcher. The informants were selected only from public higher education institutions in South Africa. A 
total of 53 informants provided data for this study. Table 2 provides a summary of the characteristics of the informants that participated in this research.

Table 2: Characteristics of the Sample

\begin{tabular}{|c|c|c|c|}
\hline & & & Total \\
\hline \multirow{4}{*}{ Age } & At most 35 years & 25 & \multirow{4}{*}{53} \\
\hline & $36-45$ years & 12 & \\
\hline & $>45$ years & 9 & \\
\hline & Did not answer the question & 7 & \\
\hline \multirow{4}{*}{ Gender } & Male & 23 & \multirow{4}{*}{53} \\
\hline & Female & 20 & \\
\hline & I prefer not to answer this question & 2 & \\
\hline & Did not answer the question & 8 & \\
\hline \multirow{3}{*}{ Type of employment } & Fulltime & 39 & \multirow{3}{*}{53} \\
\hline & Not Fulltime & 9 & \\
\hline & Did not answer the question & 5 & \\
\hline \multirow{4}{*}{ Years of experience } & At most 3 years & 14 & \multirow{4}{*}{53} \\
\hline & $4-5$ years & 8 & \\
\hline & $>5$ years & 29 & \\
\hline & Did not answer the question & 2 & \\
\hline \multirow{4}{*}{ Researcher experience } & Emerging & 45 & \multirow{4}{*}{53} \\
\hline & Intermediate developed & 4 & \\
\hline & Established & 1 & \\
\hline & Did not answer the question & 3 & \\
\hline
\end{tabular}

The research population for the study was academics who are involved in research activities. An anonymous paper-based questionnaire was distributed to academics that fell within the lead researcher's community of practice who are involved with research and supervision.

\section{Data Analysis}

The purpose of this research was to develop a better understanding of the issues that affect academics perceptions towards academic dishonesty. The first step was to test the reliability of the questionnaire. A reliability analysis was carried out on the instrument comprising 26 items. The Cronbach's alpha showed the instrument to reach acceptable reliability, $\alpha=0.791$. The statements were then ranked by the mean value.

Table 3: Statements Ranked by Mean Value

\begin{tabular}{|c|c|c|c|c|c|}
\hline 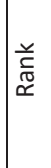 & & 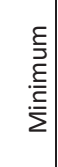 & 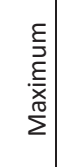 & 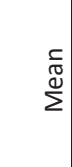 & 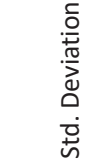 \\
\hline 1. & Q18. Copying others' work without citing them constitutes plagiarism. & 3 & 5 & 4.76 & .496 \\
\hline 2. & Q19. There are serious consequences if I violate plagiarism policy. & 2 & 5 & 4.69 & .612 \\
\hline 3. & Q15. Librarians are key academic resources. & 1 & 5 & 4.02 & 1.276 \\
\hline 4. & Q26. I feel pressured to do other university activities such as administration or community engagement & 1 & 5 & 3.90 & 1.429 \\
\hline 5. & Q16. Google Scholar is a legitimate academic resource. & 1 & 5 & 3.89 & 1.031 \\
\hline 6. & Q4. I find academic writing challenging. & 1 & 5 & 3.63 & 1.237 \\
\hline 7. & Q7. Turn-it-in is a useful tool for me to avoid plagiarism. & 1 & 5 & 3.63 & 1.121 \\
\hline 8. & Q1. I feel pressured to publish. & 1 & 5 & 3.60 & 1.261 \\
\hline 9. & Q2. I feel pressured to publish within a shorted time frame. & 1 & 5 & 3.57 & 1.323 \\
\hline 10. & $\begin{array}{l}\text { Q23. I only trust the established academic publishing companies i.e Elsevier, Springer, Wiley-Blackwell, } \\
\text { Taylor \& Francis and Sage }\end{array}$ & 1 & 5 & 3.55 & 1.170 \\
\hline 11. & Q9. I feel overwhelmed with the amount of data that I must manage. & 1 & 5 & 3.48 & 1.213 \\
\hline 12. & Q3. I feel pressured by my line manager to publish. & 1 & 5 & 3.36 & 1.331 \\
\hline 13. & Q8. iThenticate is a useful tool for me to avoid plagiarism. & 1 & 5 & 3.29 & .825 \\
\hline
\end{tabular}




\begin{tabular}{|c|c|c|c|c|c|}
\hline 14. & Q10. I find it difficult to identify false information. & 1 & 5 & 3.28 & 1.081 \\
\hline 15. & Q6. I have received insufficient training in academic writing. & 1 & 5 & 3.13 & 1.284 \\
\hline 16. & Q17. I have received insufficient training in anti-plagiarism. & 1 & 5 & 3.09 & 1.348 \\
\hline 17. & Q5. I do not understand the academic review process. & 1 & 5 & 2.91 & 1.165 \\
\hline 18. & Q11. It is ok to crowdsource aspects of my literature. & 1 & 5 & 2.87 & .921 \\
\hline 19. & Q14. The academic database interface is complicated. & 1 & 5 & 2.86 & 1.161 \\
\hline 20. & Q22. I do not trust open access journals. & 1 & 5 & 2.83 & 1.105 \\
\hline 21. & Q24. It is ok to hire a third party to collect my data. & 1 & 5 & 2.58 & 1.273 \\
\hline 22. & Q13. The language used to search academic databases is hard to learn. & 1 & 5 & 2.42 & 1.016 \\
\hline 23. & Q20. Copying my own submitted work does not constitute plagiarism. & 1 & 5 & 2.36 & 1.272 \\
\hline 24. & Q21. It is ok to hire professional academic writing services to assist me write. & 1 & 5 & 2.31 & 1.197 \\
\hline 25. & Q12. I do not understand how to use academic databases. & 1 & 5 & 2.04 & .999 \\
\hline 26. & Q25. It is ok to hire a professional to write aspects of my research. & 1 & 4 & 1.64 & .811 \\
\hline
\end{tabular}

The next step in the analysis was to administer the Levene's statistic to test homogeneity of variance for the different categories, as illustrated in Table 4. In the context of this study, the researchers wanted to investigate if the respondents had the same attitudes to issues affecting plagiarism. All $p$ values are $>0.05$, the variance can be assumed to be homogeneous.

Table 4: Levene's Test for Equality of Variances $p$ values

\begin{tabular}{|c|c|c|c|c|}
\hline & & $\begin{array}{l}\frac{1}{0} \\
\frac{0}{0} \\
\frac{0}{0} \\
0\end{array}$ & 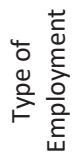 & 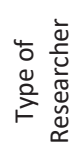 \\
\hline 1. & Pressure & .177 & .262 & .358 \\
\hline 2. & Electronic Deterrent & .425 & .716 & .048 \\
\hline 3. & Writing Challenges & .058 & .180 & .239 \\
\hline 4. & Outsourcing & .986 & .671 & .671 \\
\hline 5. & Data Challenges & .957 & .763 & .235 \\
\hline 6. & Plagiarism & .076 & .350 & .974 \\
\hline 7. & Database & .632 & .417 & .229 \\
\hline 8. & Electronic Sources & .134 & .612 & .236 \\
\hline
\end{tabular}

Finally, a One-Way ANOVA test was conducted using age as a grouping to investigate if there is a statistically significant difference between group means. For all categories the significance values are greater than 0.05 except for Database were $p=0.06$, which is below 0.05 . Therefore, there is a statistically significant difference in the mean for the category of Database.

Table 5: Summary of One-Way ANOVA - Age

\begin{tabular}{|l|l|l|l|l|l|l|}
\hline \multicolumn{7}{|c|}{ ANOVA } \\
\hline \multirow{5}{*}{ Pressure } & Sum of Squares & df & Mean Square & F & Sig. \\
\hline & Between Groups & 1.673 & 2 & .836 & .975 & .386 \\
\cline { 2 - 8 } & Within Groups & 36.902 & 43 & .858 & & \\
\cline { 2 - 8 } & Total & 38.575 & 45 & & & \\
\hline \multirow{5}{*}{ Electronic deterrent } & Within Groups & 23.951 & 2 & .397 & .712 & .496 \\
\cline { 2 - 8 } & Between Groups & .793 & 43 & .557 & & \\
\cline { 2 - 8 } & Total & 24.745 & 45 & & & \\
\hline \multirow{3}{*}{ Writing challenges } & Between Groups & 1.987 & 2 & .994 & 1.043 & .361 \\
\cline { 2 - 8 } & Within Groups & 40.969 & 43 & .953 & & \\
\hline
\end{tabular}




\section{Shawren Singh and John Mendy}

\begin{tabular}{|l|l|l|l|l|l|l|}
\hline & Total & 42.957 & 45 & & & \\
\hline \multirow{5}{*}{ Outsourcing } & Between Groups & 1.767 & 2 & .884 & 2.110 & .134 \\
\hline & Within Groups & 18.007 & 43 & .419 & & \\
\cline { 2 - 8 } & Total & 19.774 & 45 & & & \\
\hline \multirow{5}{*}{ Data challenges } & Between Groups & .368 & 2 & .184 & .412 & .665 \\
\hline & Within Groups & 19.201 & 43 & .447 & & \\
\cline { 2 - 8 } & Total & 19.568 & 45 & & & \\
\hline \multirow{5}{*}{ Databiarism } & Between Groups & .580 & 2 & .290 & .816 & .449 \\
\hline & Within Groups & 15.286 & 43 & .355 & & \\
\cline { 2 - 8 } & Total & 15.867 & 45 & & & \\
\hline \multirow{5}{*}{ Electronic sources } & Between Groups & 6.396 & 2 & 3.198 & 5.874 & .006 \\
\hline & Within Groups & 23.409 & 43 & .544 & & \\
\cline { 2 - 8 } & Total & 29.804 & 45 & & & \\
\hline & Between Groups & .606 & 2 & .303 & .980 & .383 \\
\hline & Within Groups & 13.279 & 43 & .309 & & \\
\hline & Total & 13.884 & 45 & & & \\
\hline
\end{tabular}

\section{Discussion}

When the statements were ranked by mean value, it is interesting to note that academics are aware of gross plagiarism and the consequences of plagiarism (Rank 1 and 2). (Rank 3) Academics agree that librarians are key assets in the academic enterprise. (Rank 4) Academics feel pressured to be involved with administration or community engagement and (Rank 5) academics see Google Scholar as a legitimate academic resource.

Academic seeing Google Scholar as a legitimate academic resource is a concern because Google Scholar only indexes academic papers, Google Scholar does not test the veracity of the peer review process or the credibility of the claims made in these papers. The Levene's statistic indicated that the variance can be assumed to be homogeneous, this means the respondents had the same perceptions about the issues that they were asked about. Finally, the One-Way ANOVA by Age indicated the DataBase has a difference between age groups. Further investigation is required as to the nature of these differences between the groups. This preliminary research confirms ongoing concerns about academic dishonesty (Singh, 2015, 2017; Singh and Remenyi, 2016; Casadevall, 2019).

\section{Limitations of this study}

This study has two limitations. The first is that in this study data was only collected from informants in the public sector higher education space in South Africa. No special effort was made to collect data from private higher education institutes in South Africa. The second limitation is that the sample size is 53, it is not possible to conduct sophisticated statistics analysis, such as factor analysis (MacCallum et al., 1999; Mundfrom, Shaw and Ke, 2005), with a sample of 53 informants. However, this preliminary data does give us insight into how these researchers perceive the issues related to plagiarism.

\section{Conclusion}

The initial findings of this research indicate that academic dishonesty is complex and affected by several factors. The surveyed informants are aware of the issues related to academic dishonesty.

In summary, as outlined in Figure 3, the surveyed researchers are aware of: (1) the negative effects of plagiarism, (2) the value of key stakeholders in managing the data challenge issues. Researchers acknowledge that they feel increasing (3) academic pressure and follow the path of least resistance when it comes to sourcing academic literature by using (4) electronic sources. Researchers find it difficult to (5) write and have unrealistically faith in (6) electronic deterrents to protect them from plagiarism. Researchers acknowledge that 
(7) outsourcing aspects of their research to outside parties is a form of academic dishonesty and finally researchers have a respectable understanding of (8) academic databases.

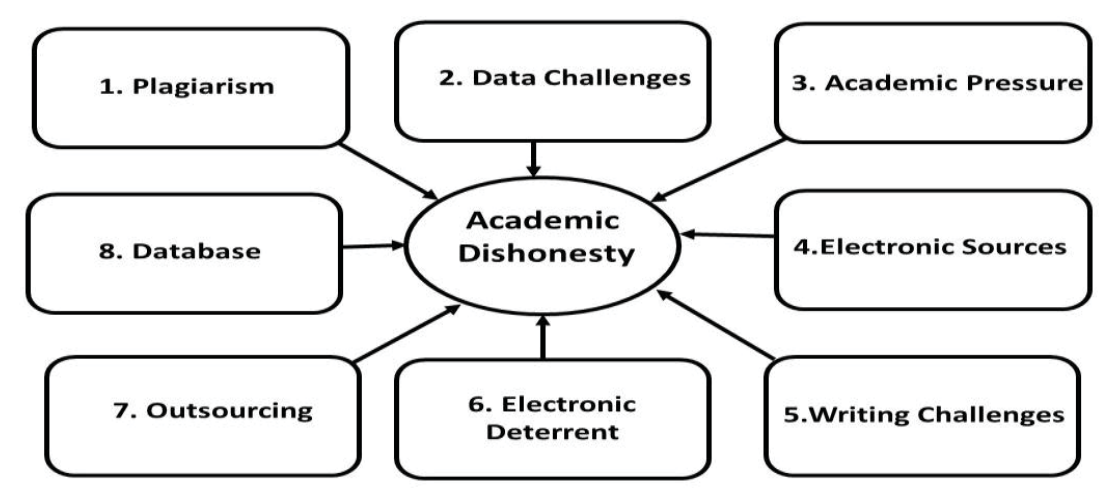

Figure 3: Factors Affecting Academic Dishonesty Revised

It is interesting to note that one of the anonymous reviews pointed out that "perhaps the paper should address types of policies that a university could put in place to ensure that dishonesty is minimised," universities have moved from a self-policing system to a policy-driven system to discourage academic dishonesty. However the same reviewer pointed out that "Of course there is the problem inherent in the system which I face some years ago when I asked for a plagiarism check on some work that I was examining but I was told that my request for this plagiarism test could be interpreted as impugning the integrity of the student." Policies are only as good as people's acceptance of these policies. Academic dishonesty is a challenge that cannot be driven away solely by policy, but probably, by a combination of academic attitudes and policy. Respectable research is generally recognised by peers, research methodology and academic writing cannot be regulated - research methodology and academic writing can be used to either honestly support the research endeavour or dishonesty prop up research.

\section{References}

Aitchison, C. (2015) 'Writing the Practice/Practise the Writing: Writing challenges and pedagogies for creative practice supervisors and researchers', Educational Philosophy and Theory. Routledge, 47(12), pp. 1291-1303. doi: 10.1080/00131857.2015.1035629.

Babakus, E. and Mangold, W. G. (1992) 'Adapting the SERVQUAL scale to hospital services: an empirical investigation.', Health services research, 26(6), pp. 767-86. Available at:

http://www.ncbi.nlm.nih.gov/pubmed/1737708\%0Ahttp://www.pubmedcentral.nih.gov/articlerender.fcgi?artid=PMC 1069855.

Bouranta, N., Chitiris, L. and Paravantis, J. (2009) 'The relationship between internal and external service quality', International Journal of Contemporary Hospitality Management, 21(3), pp. 275-293. doi: 10.1108/09596110910948297.

Casadevall, A. (2019) 'Huge misconduct fine is a reminder to reward rigour', Nature, 568(April), p. 7.

Cawood, F. et al. (2008) 'A perspective on university academic workload measurement', 40(2), pp. 153-179.

Clarke, R. (2006) 'Plagiarism by academics: More complex than it seems', Journal of the Association for Information Systems, 7(1).

Devlin, S. J., Dong, H. K. and Brown, M. (1993) 'Selecting a scale for measuring quality', Marketing Research, 5(3), pp. 1217.

Dinis-Oliveira, R. J. and Magalhães, T. (2016) 'The Inherent Drawbacks of the Pressure to Publish in Health Sciences: Good or Bad Science', F1000Research, 4(1), p. 419. doi: 10.12688/f1000research.6809.2.

Grimes, D. R., Bauch, C. T. and loannidis, J. P. A. (2018) 'Modelling science trustworthiness under publish or perish pressure Subject Category : Subject Areas : Author for correspondence':, Royal Society Open Science, 5(171511). Available at: http://dx.doi.org/10.1098/rsos.171511.

Head, M. L. et al. (2015) 'The Extent and Consequences of P-Hacking in Science', PLoS Biology, 13(3), pp. 1-15. doi: 10.1371/journal.pbio.1002106.

Hedding., D. W. (2019) 'Payouts push professors towards predatory journals', Nature, 565(January), p. 267.

Husain, F. M., Al-Shaibani, G. K. S. and Mahfoodh, O. H. A. (2017) 'Perceptions of and Attitudes toward Plagiarism and Factors Contributing to Plagiarism: a Review of Studies', Journal of Academic Ethics. Journal of Academic Ethics, 15(2), pp. 167-195. doi: 10.1007/s10805-017-9274-1.

Jarić, I. (2016) 'High time for a common plagiarism detection system', Scientometrics, 106(1), pp. 457-459. doi: 10.1007/s11192-015-1756-6.

Jeyaraj, J. J. (2018) 'SOCIAL SCIENCES \& HUMANITIES Improving Academic Writing Standard : A Challenge for Universities', Journal of Language Studies, 18(1), pp. 22-37. Available at: http://doi.org/10.17576/gema-2018-1801-02. 
Jinha, A. E. (2010) 'Learned Publishing', Learned Publishing, 23(3), pp. 258-63.

Kalnins, A. U., Halm, K. and Castillo, M. (2015) 'Screening for self-plagiarism in a subspecialty-versus-general imaging journal using iThenticate', American Journal of Neuroradiology, 36(6), pp. 1034-1038. doi: 10.3174/ajnr.A4234.

Kornhaber, R. et al. (2016) 'The benefits and challenges of academic writing retreats: an integrative review', Higher Education Research and Development. Taylor \& Francis, 35(6), pp. 1210-1227. doi: 10.1080/07294360.2016.1144572.

Lammey, R. (2014) 'CrossRef developments and initiatives: an update on services for the scholarly publishing community from CrossRef', Science Editing, 1(1), pp. 13-18. doi: 10.6087/kcse.2014.1.13.

Lei, J. and Hu, G. (2014) 'Chinese ESOL lecturers' stance on plagiarism : does knowledge', 68(January), pp. 41-51. doi: 10.1093/elt/cct061.

MacCallum, R. C. et al. (1999) 'Sample size in factor analysis', Psychological Methods, 4(1), pp. 84-99. doi: 10.1037/1082989X.4.1.84.

Molet, M. et al. (2013) 'Guilt by association and honor by association : The role of acquired equivalence', pp. 385-390. doi: 10.3758/s13423-012-0346-3.

Mouton, J. (2017) 'The extent of South African authored articles in predatory journals', 113(7), pp. 1-9.

Mundfrom, D. J., Shaw, D. G. and Ke, T. L. (2005) 'Minimum Sample Size Recommendations for Conducting Factor Analyses Minimum', International Journal of Testing, 5(2), pp. 159-168. doi: 10.1207/s15327574ijt0502.

Myers, M. D. (2009) 'Qualitative research in Business \& Management'. Los Angeles: Sage.

Randall, M. (2001) Pragmatic plagiarism: Authorship, profit, and power. University of Toronto Press.

Remenyi, D. (2017) Dictionary of research concepts and issues. Reading, UK: Academic Conferences and Journals International Limited.

Remenyi, D. and Susan, G. (2016) Social media and digital scholarship for academic research: a user's guide. Reading, UK: Academic Conferences and Publishing International.

Robinson-Zañartu, C. et al. (2005) 'Academic crime and punishment: Faculty members' perceptions of and responses to plagiarism.', School Psychology Quarterly, 20(3), pp. 318-337. doi: 10.1521/scpq.2005.20.3.318.

Sachdev, S. B. and Verma, H. V (2004) 'Relative importance of service quality', Journal of Services Research, 04(01), pp. 93116.

Santoso, A. and Cahaya, F. R. (2018) 'Factors influencing plagiarism by accounting lecturers', Accounting Education, pp. 125. doi: 10.1080/09639284.2018.1523736.

Sarwar, S. and Idris, Z. M. (2018) 'Paid Academic Writing Services : A Perceptional Study of Business Students', (July). doi: 10.22555/ijelcs.v3i1.2078.

Singh, S. (2015) 'The zombie doctorate', in ECRM2015-Proceedings of the 14th European Conference on Research Methods 2015: ECRM 2015. Academic Conferences Limited, p. 352.

Singh, S. (2017) 'The art of Being a Polycephalic Researcher', in ECRM 2017 16th European Conference on Research Methods in Business and Management. Academic Conferences and publishing limited, p. 331.

Singh, S. and Remenyi, D. (2016) 'Plagiarism and ghostwriting: The rise in academic misconduct', South African Journal of Science. Academy of Science of South Africa, 112(5-6), pp. 1-7.

Supak Smolcic, V. and Simundic, A.-M. (2013) 'Biochemia Medica has started using the CrossCheck plagiarism detection software powered by iThenticate', Biochemia Medica, 23(2), pp. 139-140. doi: 10.11613/bm.2013.016.

W1 (2019) What is academic dishonesty?, Berkeley City College. Available at: https://www.berkeleycitycollege.edu/wp/de/what-is-academic-dishonesty/ (Accessed: 9 May 2019).

W2 (2019) Plagiarism \& Academic Integrity: Types of Academic Dishonesty, St. Petersburg College. Available at: https://spcollege.libguides.com/c.php?g=254383\&p=1695452\#disruptivebehavior (Accessed: 9 May 2019).

W3 (2019) Plagiarism Tutorial, Duke University. Available at: https://plagiarism.duke.edu/unintent/ (Accessed: 10 May 2019).

W4 (2018) Flawed research methods exaggerate the prevalence of depression, Canadian Medical Association Journal, ScienceDaily. Available at: www.sciencedaily.com/releases/2018/01/180115094237.htm (Accessed: 10 May 2019).

W5 (2011) Flaws in popular research method exposed, University of Leicester, ScienceDaily. Available at: www.sciencedaily.com/releases/2011/02/110210075726.htm (Accessed: 10 May 2019).

Yin, R. K. (2011) 'Qualitative Research from Start to Finish'. New York: The Guilford Press. 